\title{
TRITIUM INVENTORY OF A TARGET FACTORY IN AN ICF POWER PLANT
}

John W. Sher ahman

LAWRENCE LIVERMORE NATIONAL LABORATORY

P. O. Box 5508

Livermare, CA 94550

\begin{abstract}
A preliminary parametric study has been performed to estimate the tritium inventory of a con,jectured Target Factory. The inventory of a proposed tritiated fuel processing system was determined as a function of production efficiency, storage factor, and time interval for the slowest: processing step. Results indicated that a study of this type will be haneficial in evaluating possible processing schemes for the production of tritiated laser fusion targets.
\end{abstract}

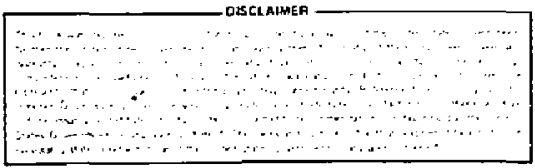




\section{INTRODUCTION}

Parametric expressions have been derived for target production and tritium processing in a Target Factory. $(1,2)$ The input and output rate of a process system, the efficiency of a process step, and the number of process steps and production lines are parameters that have been used to formulate equations representing the tritium inventory involved in target production. From these tritium inventory equations, a parametric study is performed to estimate the quantity of tritium needed in the operation of a proposed tritiated fuel processing system during the production mode of a Target Factory.

\section{TARGET FACTORY TRITIUM SYSTEM}

A proposed tritium system to process fuel during target production is shown in Figure 1. A description of this system alang with the derivation of the tritium inventory equations are given in Reference (1).

\section{Source}

The tritium source supplies fuel to the fill process section. In a steady state production mode, the source output rate $\dot{m}_{S}$ to the $f i l l$ process section is equal to the sum of the tritium input rates $\dot{m}_{R}$ from recovery and $\dot{m}_{E}$ from the reactor,

$$
\dot{m}_{S}=\dot{m}_{R}+\dot{m}_{E}
$$


From equation (1), the tritium source inventory during production can he spt to a minimal level and is therefore considered negligible.

\section{Fill Process}

The inventory of tritium in the fill process section during target production is given hy the expressinn:

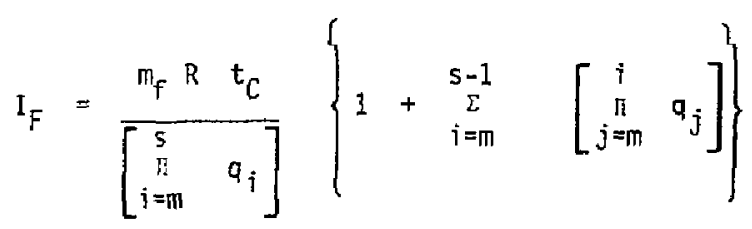

$$
\begin{aligned}
& \text { where } m_{f}=\text { amount of tritium per arget } \\
& R=\text { target injection rate into the reactor } \\
& t_{C}=\text { time interval for the llowest processing step in the } \\
& \text { cryogeric production line } \\
& q=\text { production efficiency for a cryogen ic process step (yie }{ }^{d} \\
& \text { fartor) } \\
& s=\text { The number of process steps in a cryogenic production 7ine } \\
& m=\text { the cryogen ic process step where the tritiated fue } 1 \\
& \text { processing begins. }
\end{aligned}
$$

\section{Storage}

The storage section has an invertory of tritium filled targets for the purpose of maintaining the reactor target injection rate in case of a production interruption. The tritim inventory expression is 


$$
i_{S}=m_{f} N R t_{C}
$$

where $N$ is the number of additional times that the fill process section is activated to meet a required stockpile of targets.

Recovery

The recovery section is composed of two parts: the recovery proces sind of rejected tritiated targets from the fill process section and $a$ redundant recovery system (RRS). The RRS is considered to be an environmental gas purification and/or gettering system.

The tritium inventory $I_{R}$ for the recovery section is the sum of the tritium in the initiat recovery process and in the RRS,

$$
\left.I_{R}=\frac{\pi_{f} R t_{C}}{\left[\begin{array}{cc}
s \\
i & q_{i} \\
i=m &
\end{array}\right]}\left\{I-\left[\begin{array}{cc}
s & \pi_{i} \\
i=m & q_{i}
\end{array}\right]\right\} 2-\left[\begin{array}{cc}
x & r_{i} \\
i=1 &
\end{array}\right]+\underset{i=1}{x-1}\left[\begin{array}{cc}
i \\
i=1 & r_{j}
\end{array}\right]\right\}(4)
$$

where $x$ is the number of process steps in the in itial recovery processing and $r$ represents the efficiency of exh process step.

\section{TARGET FFCTORY TRITIUM INVENTORY}

The Target factory tritium inventory may be estimated using equations (2), (3), and (4). However, to utilize these expressions, a proposed 
tritium system must be conjectured hy arbitrarily assigning values to certain parameters. Consequent1y, a proposed Factory may be assumed to have

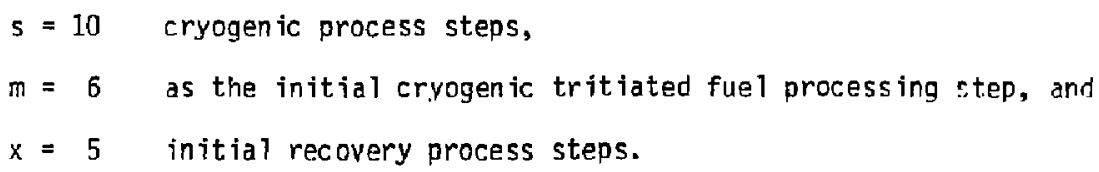

A value of $s=10$ has been selected as an estimate of the possible tota? number of processing steps in the cryogenic system that wc-1d be needed for target transport, manipulation, preparation, inspection, selection, tritium $f i 11$ and temperature treatment.

A value of $x=5$ recovery steps is select to approximate the possible number of processes to recover tritium, i.e. crushing, separating, gettering, purifying, etc.

Also, for simpicity, each step in a pracessing system is assumed to be equally efficient, $q_{j}=r_{i}$.

From expressions (2), (3), and (4), a series of plots of the ratio of tritium inventory to tritium injection rate $\left(m_{f} R\right)$ as a function of $t_{C}$ have been constructed. Figure 2 shows the ratio of the tritium inventory $I_{F}$ to $m_{F} R$ of the fill process section versus $t_{C}$ for $q$ equal to 0.7 , 0.8 , and 0.9 . Figure 3 gives the ratio $I_{S} / m_{f} R$ of the storage section 
vs $t_{C}$ for $N$ equal to 1,5 , and 10 . Lirewise, Figure 4 is the tritium inventory $p$ lot due to recovery, $I_{R} / m_{f} R$ vs $t_{C}$, for $q=r=0.7,0.8$, and 0.9 .

The parameters $m_{f}$ and $R$ whose product represents the tritium injection rate into the reactor is dependent on the tritium burn fraction and the fusion power of the ICF power plant: (3)

$$
\begin{aligned}
& \dot{\mathrm{m}}_{\mathrm{b}}=1.73 \times 10^{-6} \mathrm{p}_{f} \\
& \mathrm{~m}_{f} \mathrm{R}=\frac{\dot{m}_{b}}{\mathrm{f}_{b}}
\end{aligned}
$$

Sutstitution of (5) into (6),

$$
m_{f} R=1.78 \times 10^{-6} \frac{P_{f}}{\frac{f_{h}}{2}}
$$

$$
\text { where } \begin{aligned}
\dot{m}_{b} & =\text { tritium burn rate }(g / s) \\
\dot{p}_{f} & =\text { fusion power }\left(M W_{f}\right) \\
f_{b} & =\text { hurn fraction }
\end{aligned}
$$

For a given vatue of $t_{C}$ and $m_{f} R$, the tritium inventory of each of the sections can be determined from these plots. 
For instance, if it is assumed that an ICF power plant operates at $P_{f}=3,000 N_{f}$ with a burn fraction $f_{b}=0.3$, the tritium injection rate from equation (7) becomes

$$
m_{f} R=0.0178 \mathrm{~g} / \mathrm{s}
$$

Furthermore, if the proposed Target Factory operates at a 0.9 effic iency with a storage factor of $N=10$, the tritium inventories of each section $c$ an be determined using $(2),(3)$, and (4) for various values of $t_{C}$ as showr in Table 1 . The total tritium inventory $I_{T}$ from Table 1 is

TABLE 1

Tritium Inventory of a Proposed Target Factory Operating to Maintain a $3,000 \mathrm{MW}_{\mathrm{f}}$ ICF Power Plant ${ }^{*}$

\begin{tabular}{|c|c|c|c|c|}
\hline $\begin{array}{c}\mathrm{t}_{\mathrm{C}} \\
(\mathrm{hr})\end{array}$ & $\begin{array}{c}\mathrm{I}_{\mathrm{F}} \\
(\mathrm{Kg})\end{array}$ & $\begin{array}{c}\mathrm{IS}_{\mathrm{g}} \\
(\mathrm{Kg})\end{array}$ & $\begin{array}{c}\mathrm{I}_{\mathrm{R}} \\
(\mathrm{Kg})\end{array}$ & $\begin{array}{c}\mathrm{IT}_{\mathrm{T}} \\
(\mathrm{Kg})\end{array}$ \\
\hline 0.5 & 0.22 & 0.32 & 0.10 & 0.84 \\
1.0 & 0.44 & 0.64 & 0.20 & 1.08 \\
10.0 & 4.46 & 6.41 & 2.01 & 12.88 \\
\hline
\end{tabular}

$\star_{q_{j}}=r_{j}=0.9$ 
plotted in Figure 5 as a function of $t_{C}$. The time interval for the slowest pracessing step in the cryogen ic production $T$ ine is shown to be an important factor in determining the total inventory of tritium. Consequentil $v$, cryogenic production must be thought of in terms of processes that will result in a minimal value for $t_{C}$.

Likewise, the operating efficiency of the Target Factory is also an important factor in determining the total tritium inventory as show in Table 2. The numbers are based on an arbitrary assigned value of one hour for ${ }^{t} C$.

TABLE 2

Tritium Inventory of a Proposed Target Factory Operating at Various Efficiencies While Interfacing a 3,000 MWf Power Plant*

\begin{tabular}{|l|l|l|l|l|}
\hline$q_{i}=r_{i}$ & $I_{F g}$ & $\begin{array}{c}I_{S} \\
(\mathrm{Kg})\end{array}$ & $\begin{array}{c}\mathrm{IR}_{\mathrm{R}} \\
(\mathrm{Kg})\end{array}$ & $\begin{array}{c}\mathrm{I}_{\mathrm{T}} \\
(\mathrm{Kg})\end{array}$ \\
\hline 0.9 & 0.44 & 0.64 & 0.20 & 1.08 \\
0.8 & 0.55 & 0.64 & 0.53 & 1.82 \\
0.7 & 1.06 & 0.64 & 1.14 & 2.84 \\
\hline
\end{tabular}

$\star t_{r}=1 \mathrm{hr}$

It is of interest to note from both Table 1 and Table 2 that the total tritium inventory could lie in the kilogram range. Becalıse con- 
straints will indubitably be placed on the quantity of tritium allowable, high efficiency, and high rate processes must be developed. A parametric study will he necessary to evaluate possible processes for target production to estimate the totâl tritium inventory of a tritiated fuel system.

\section{SUMMARY}

From derived expressions, the inventory of tritium involved in the processing of laser fusion targets can be estimated for given values of production parameters. In the case of a proposed Target Factory, it was found that the inventory could very wall be in the range of tens of kilograms of tritium depending on production efficiency and characteristic time interval for processing. A parametric study of this type will be beneficial in evaluating poss ible production process schemes.

\section{ACKNOWLEDGEMENTS}

The author would like to thank $W$. Meier for his very helpful discussions and C. D. Hendricks for his continual support. 


\section{REFERENCES}

1. J. W. Sherohman and W. R. Meier, "A Parametric Study of a Target Factory for Laser Fusion", l.aurence Livermore Natinnal Laboratory, UCRL-84264, Oc tober 8, 1980.

2. J. W. Sherohman, "Parametr ic Expressions of Tritium Flow Rates and Inventories in a Target Factory", Lawrence Livermore National Laboratory, vitio-18857, bec enther ą, 3980 .

3. W. R. Meier, "Fusion Energy Conversion Factors and HYLIFE Parameters", E\&MA Report 79-143, November 20, 1979. 


\section{FIGURE CAPTIONS}

Fig. 1 A basic black diagram of a tritium system interfacing a cryogen ic process of a Target Factory.

Fig. 2 Tritium inveritory plot for the fill process section.

Fig. 3 Tritium inventory piot for the storage section.

Fig. 4 Tritiun inventory plot for the recovery section.

Fig. 5 Total tritium inventory plot of the proposed tritiated fuel processing system. 


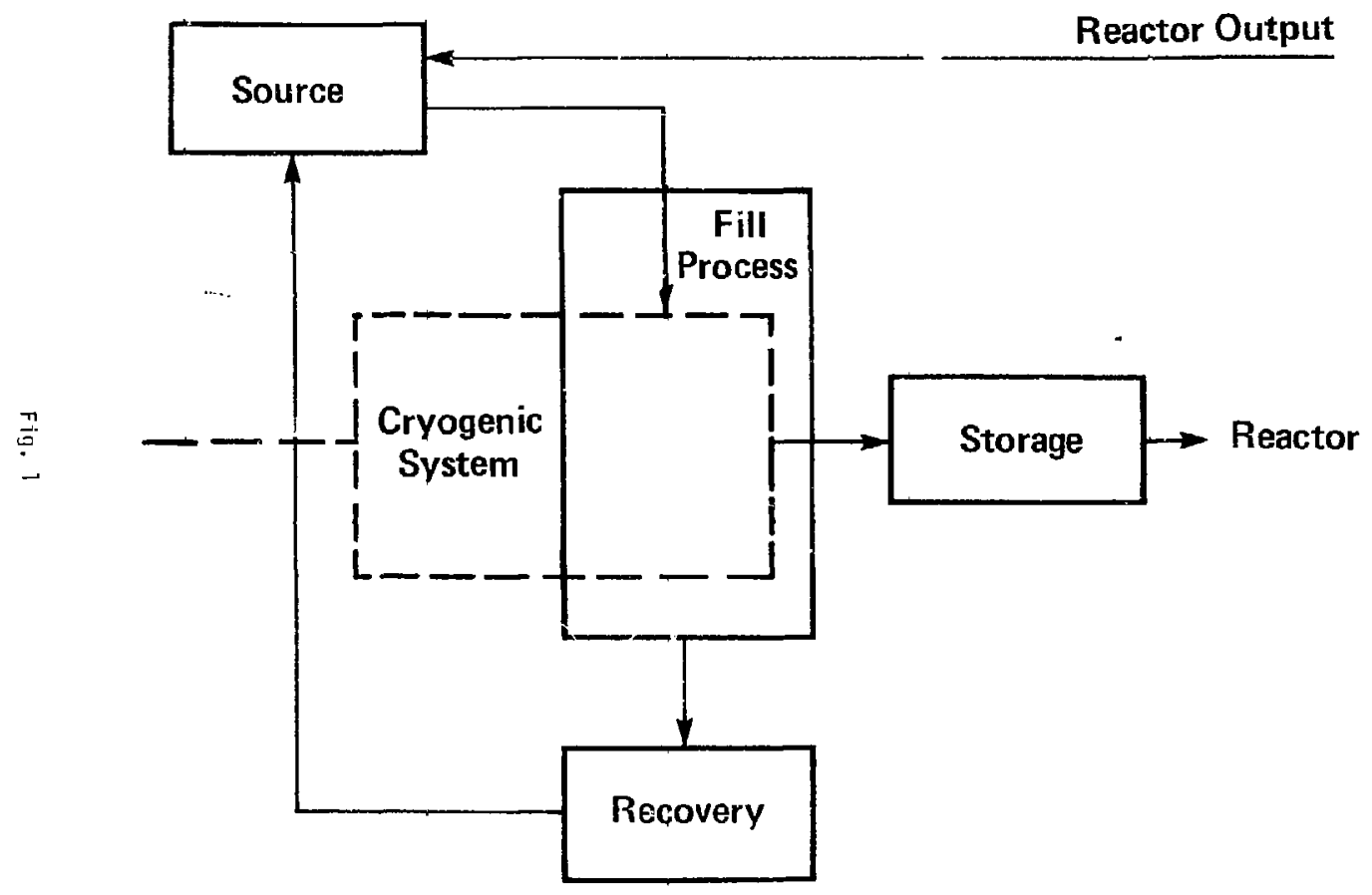




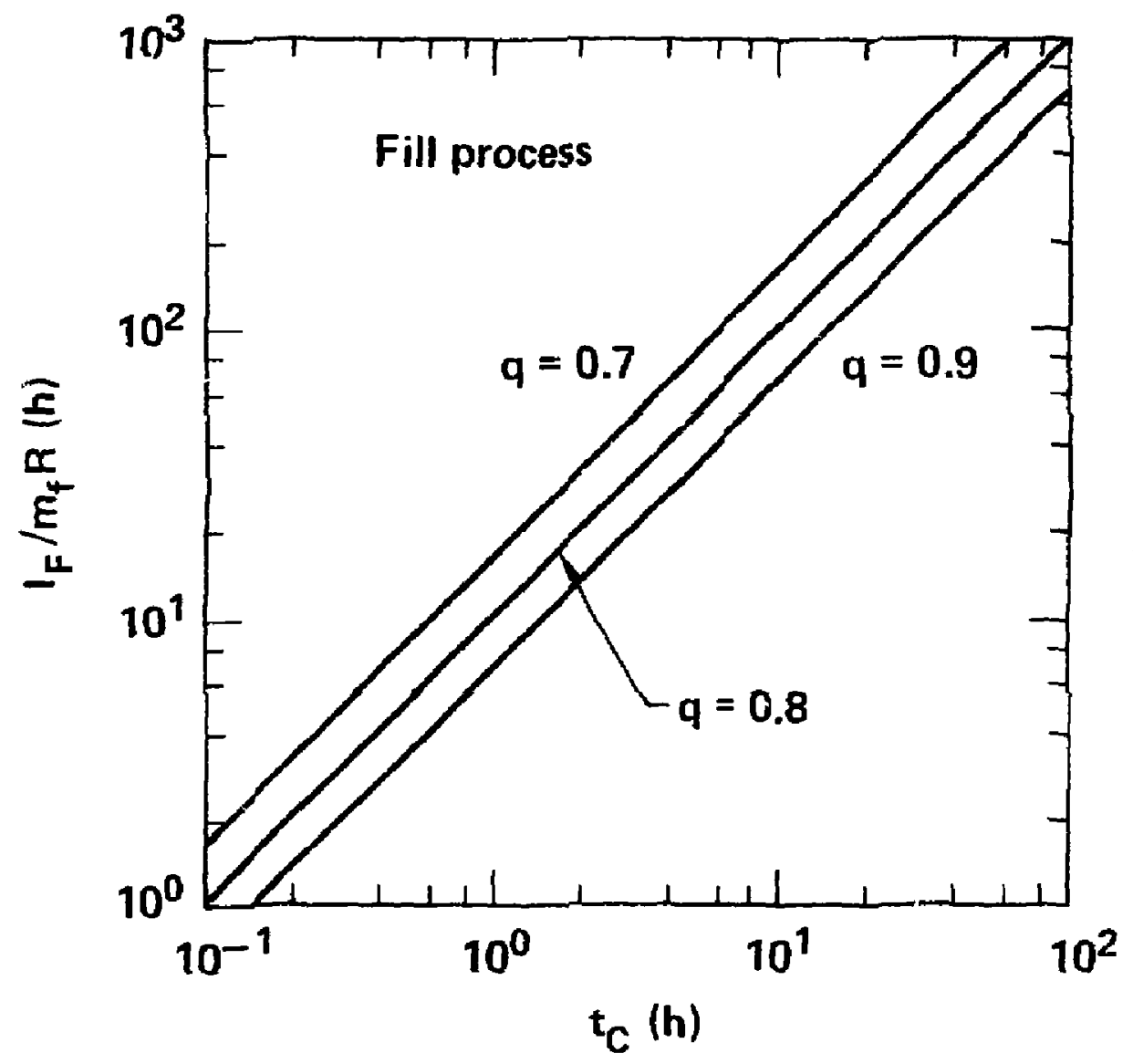

Fig. 2 


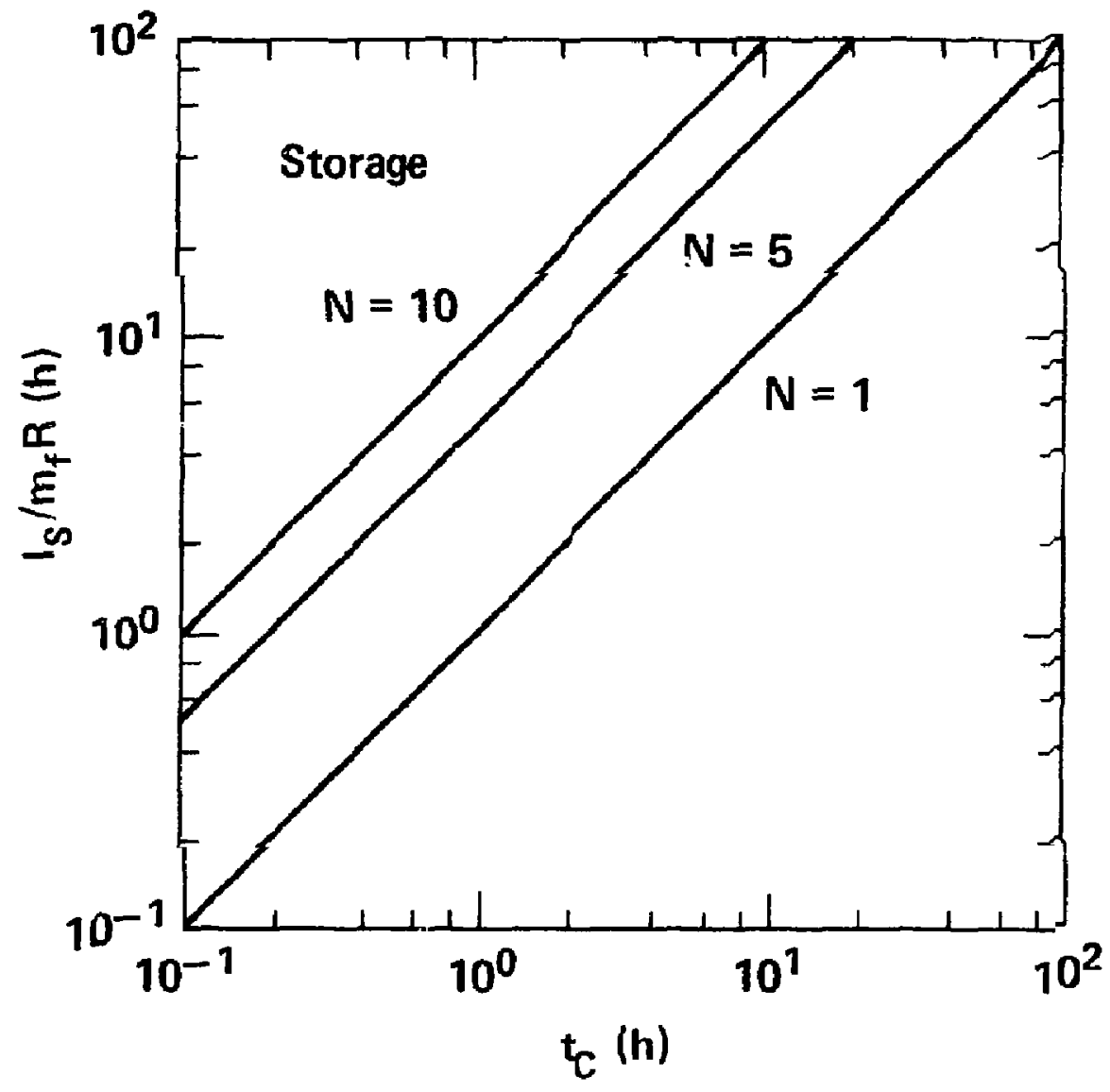

Eig. 3 


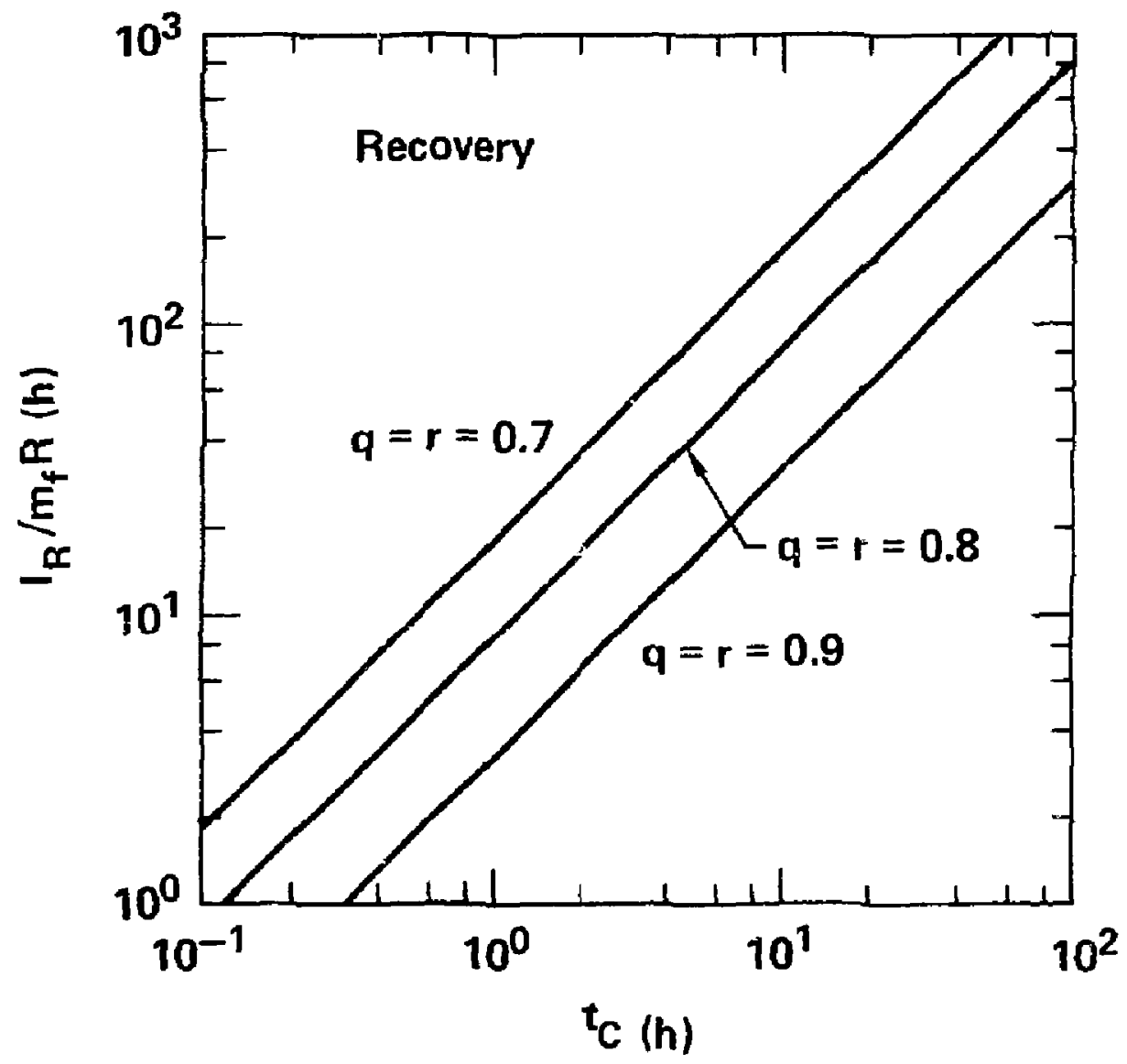

Fig. 4 


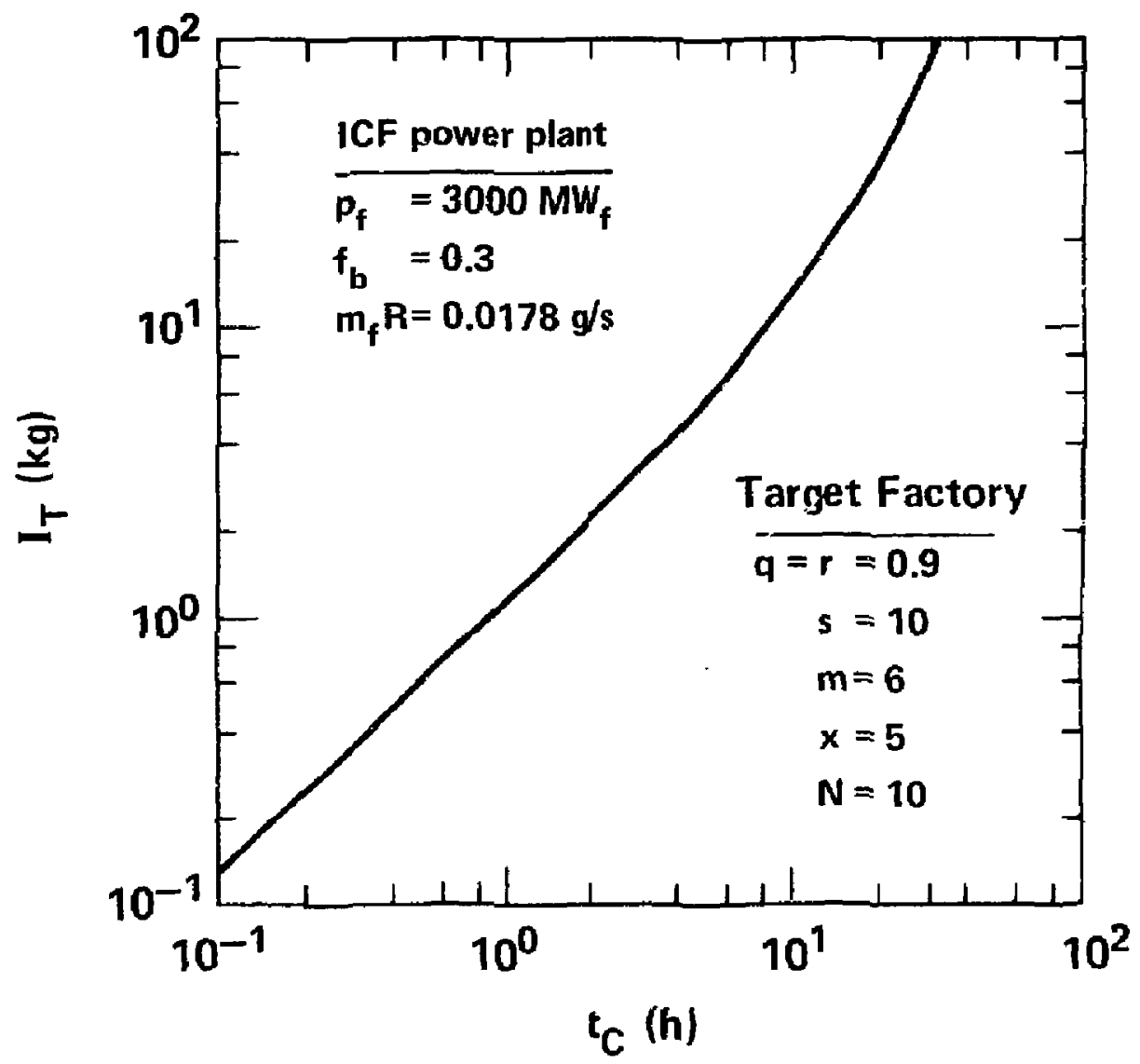

Fig. 5 